\title{
Asymmetric epoxidation using a singly-bound supported Katsuki-type (salen)Mn complex
}

\author{
Keith Smith* and Chia-Hui Liu \\ Centre for Clean Chemistry, Department of Chemistry, University of Wales Swansea, Swansea, UK SA2 \\ 8PP.E-mail:k.smith@swansea.ac.uk
}

Received (in Cambridge, UK) 7th January 2002, Accepted 12th February 2002

First published as an Advance Article on the web 25th March 2002

We have successfully prepared an unsymmetrical analogue of a Katsuki-type salen ligand having a single hydroxyalkyl group at its 6-position, and also its Mn(III) complex; attachment of the complex to a polymer gives a highly enantioselective and recoverable catalyst for epoxidation of 1,2-dihydronaphthalene.

Enantioselective epoxidation using chiral (salen)Mn(III) complexes has become a useful preparative method in organic synthesis. ${ }^{1,2}$ Chiral (salen)Mn complexes developed by Jacobsen, Katsuki, and co-workers are effective catalysts for asymmetric epoxidation of alkenes with high levels of enantioselectivity.1,2 However, such homogeneous catalysts are not easily recovered for reuse or recycle. By contrast, heterogeneous catalysts offer easy separation from products and facile recovery for recycling.

Recently, increasing interest has been shown in the development of polymer-supported chiral catalysts. ${ }^{3}$ Several researchers have investigated the immobilisation of analogues of Jacobsen homogeneous catalysts onto solid supports for use as recyclable catalysts in asymmetric epoxidation of alkenes. ${ }^{4}$ Unfortunately, immobilization of these catalysts often causes significant decreases in the enantioselectivity they display or the complexes are anyway not stable enough to allow recycling. Therefore, there is still a major need for a stable, recyclable, polymer-supported, homochiral (salen)Mn complex. Furthermore, as far as we are aware no attempt has previously been made to immobilize a Katsuki-type complex. We now report the synthesis and use of such a complex.

As our target complex for attachment to a polymer we chose 1, an analogue of the Katsuki complex 2, for the following reasons: i) no supported Katsuki-type complexes have previously been prepared so their properties are unknown; ii) Katsuki-type complexes give higher enantioselectivities for epoxidation of certain types of alkenes than Jacobsen-type complexes; ${ }^{2 a}$ iii) the Katsuki-type complexes are bulky molecules and may be less prone to oxidative dimerisation; 5 iv) the steric hindrance may also render the ligand more stable to decomposition; v) with only a single site for attachment of the complex to a support, all catalytic sites should behave in a similar manner; vi) the hydroxyalkyl group would allow attachment to several different kinds of support; vii) there would be a need to develop new procedures to overcome challenges involved in the successful synthesis of $\mathbf{1}$.

The approach to 1 required coupling known compound 3 with 1,2-cyclohexanediamine (4), then coupling intermediate (5) with novel compound 6 (Scheme 1). Scheme 2 shows the route to 6 . The side-chain was introduced by regiospecific bromination of 9 followed by a Heck reaction with methyl acrylate and then reduction to give 11. The remaining steps were analogous to those used in the synthesis of $\mathbf{3}^{6}$

Like others, ${ }^{7}$ we are sceptical about early literature claims for synthesis of unsymmetrical salen ligands. Initially we attempted synthesis of half-salen ligand $\mathbf{5}$, but it proved difficult to purify. Thus, we generated a mixture of 7 and its symmetrical analogues and separated them by column chromatography in the presence of cyclohexanediamine. Ligand 7 was successfully converted into its $\mathrm{Mn}$ complex, 1, by treatment with
$\mathrm{Mn}(\mathrm{OAc})_{2} \cdot 4 \mathrm{H}_{2} \mathrm{O}$ in air followed by ion-exchange with $\mathrm{NaPF}_{6}$. 1 could be purified by chromatography without problem.

Merrifield's resin (chloromethylated polystyrene, $1 \%$ crosslinked, 200-400 mesh, ca. 2 mmol g-1 Cl, ex Aldrich) was used in attempts to support the complex. Unfortunately, attempts to form a simple ether link between a model compound and benzyl chloride, under conditions that would be appropriate for use with the complex, produced mixtures containing dibenzyl ether. This could have given additional cross-linking in the polymeric version. Therefore, we decided instead to form an ester link using polystyrene carboxyl chloride. Standard procedures were used to convert Merrifield's resin into polystyrene carboxyl chloride. ${ }^{8}$ The resin obtained was characterised by its IR spectrum and estimated by hydrolysis and titration of liberated $\mathrm{HCl}$. This indicated a loading of $1.17 \mathrm{mmol} \mathrm{g}^{-1}$ of chloride.

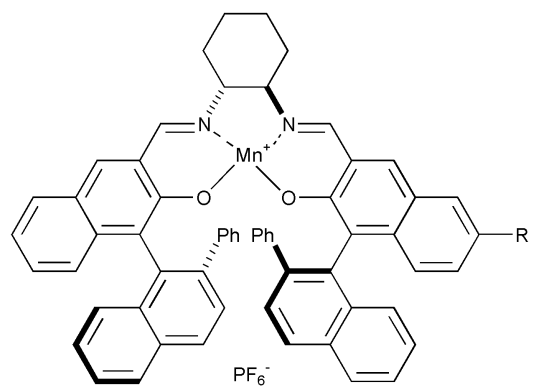

$1 \mathrm{R}=\mathrm{CH}_{2} \mathrm{CH}_{2} \mathrm{CH}_{2} \mathrm{OH}$

$2 \mathrm{R}=\mathrm{H}$

$12 \mathrm{R}=\mathrm{CH}_{2} \mathrm{CH}_{2} \mathrm{CH}_{2} \mathrm{OCOC}_{6} \mathrm{H}_{4}-\mathrm{P}$

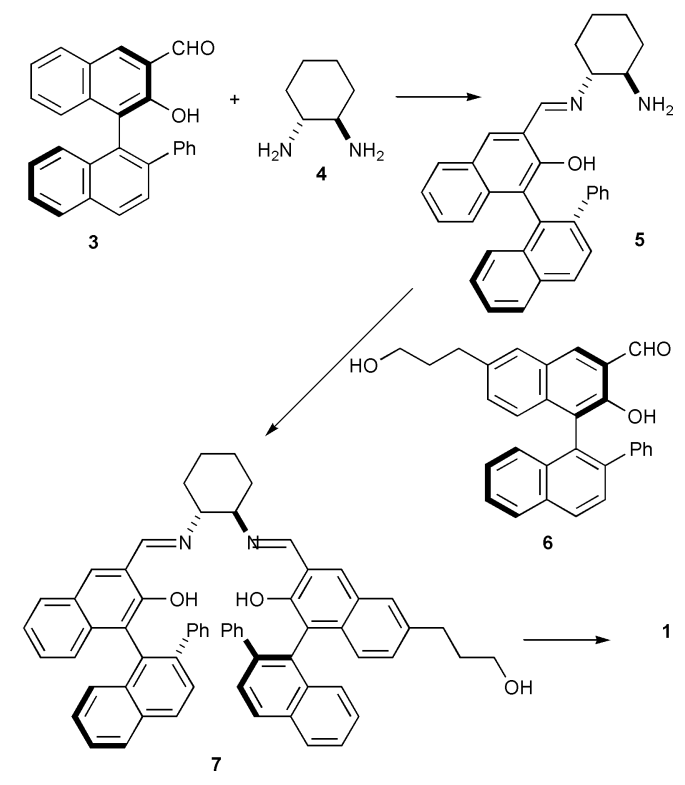

Scheme 1 Synthetic approach to unsymmetrical ligand 7, which was obtained in $83 \%$ yield based on $\mathbf{6}$ after purification by chromatography. 

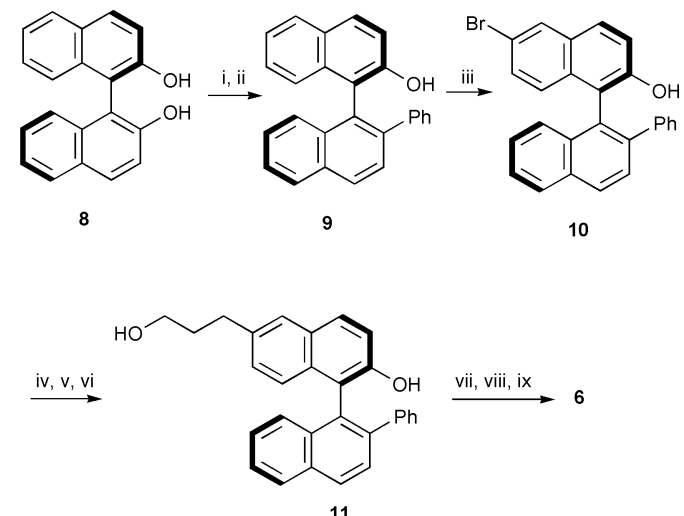

11

Scheme 2 Reagents: i) $\mathrm{Tf}_{2} \mathrm{NPh}, 2,4,6$-collidine, DMAP, $\mathrm{CH}_{2} \mathrm{Cl}_{2}$, reflux, 24 h; ii) $\mathrm{PhMgBr}, \mathrm{NiCl}_{2}$ (dppe), $\mathrm{Et}_{2} \mathrm{O}$, reflux, 2h; iii) $\mathrm{Br}_{2}$; iv) methyl acrylate, $\mathrm{Pd}(\mathrm{OAc})_{2}, \mathrm{P}(o \text {-tol })_{3}, \mathrm{CH}_{3} \mathrm{COONa}, \mathrm{DMF}, 130{ }^{\circ} \mathrm{C}$; v) $\mathrm{Mg} / \mathrm{CH}_{3} \mathrm{OH}$; vi $\mathrm{LiAlH}_{4}$ /ether; vii) $i$ - $\mathrm{Pr}_{2} \mathrm{NEt}, \mathrm{CH}_{3} \mathrm{OCH}_{2} \mathrm{Cl}, \mathrm{CH}_{2} \mathrm{Cl}_{2}$; viii) $t$-BuLi, THF, -78 ${ }^{\circ} \mathrm{C}, 3 \mathrm{~h}$, then DMF, $20{ }^{\circ} \mathrm{C} 1 \mathrm{~h}$; ix) $\mathrm{Me}_{3} \mathrm{SiBr}, \mathrm{CH}_{2} \mathrm{Cl}_{2}$.

After attachment of complex 1, the polymer (12) was estimated by determination of the Mn concentration by atomic absorption spectroscopy (AAS). A sample was calcined at 550 ${ }^{\circ} \mathrm{C}$ to produce an ash, which was treated with a mixture of hydrochloric and nitric acids (3:1), heated to dryness, dissolved in distilled water and diluted to an appropriate volume. AAS of the solution was compared with a calibration curve to give the amount of Mn present. The results indicated that the polymer contained around $0.24 \mathrm{mmol} \mathrm{g}^{-1} \mathrm{Mn}$, corresponding to about $45 \%$ incorporation of the salen complex.

The catalytic activity and selectivity of the immobilised chiral (salen)Mn complex were tested in the epoxidation of 1,2-dihydronaphthalene using sodium hypochlorite $(\mathrm{NaOCl})$ as oxidant and 4-phenylpyridine $\mathrm{N}$-oxide (4-PPNO) as activator (Scheme 3) $\dagger$ under conditions analogous to those used by Katsuki for related homogeneous catalysts. ${ }^{6}$ After reaction, the polymer was recovered and reused several times (Table 1$). \dagger$

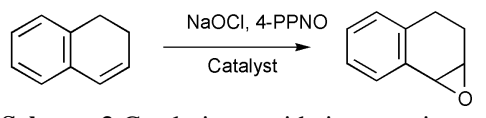

Scheme 3 Catalytic epoxidation reactions.

The results show that the polymer-supported catalyst exhibited lower rate-enhancement than with homogeneous ones. This will be partly a result of the somewhat more dilute conditions for the soluble reagents when the polymer was used, and partly the result of slow diffusion. However, enantioselectivities with the polymeric catalyst were entirely analogous to those obtained with the homogeneous ones.

Furthermore, there was no significant change in enantioselectivity on reuse of the catalyst. The amount of polymer recovered was always less than that used at the outset because of physical losses resulting from electrostatic problems during polymer recovery. Also, samples were destroyed when analyses were carried out at various times. Therefore, for re-use experiments, the amounts of alkene, $\mathrm{NaOCl}$ and 4-PPNO were all scaled down in order to maintain the same ratio with the catalyst. However, in order to maintain convenient stirring, the solvent amount was maintained at the same level, except for in the last two entries of the Table. The reactions with recovered polymer were slower as a result of the lower concentrations used. However, the enantioselectivities were only slightly lower even after the polymer had been in contact with the basic hypochlorite solution for up to 10 days in total.

We conclude that the polymer-supported Katsuki-type catalyst is quite stable over long periods even in basic conditions. This conclusion is supported by AAS measurement of the
Table 1 Asymmetric epoxidation of 1,2-dihydronaphthalene using polymer $12^{a}$

\begin{tabular}{|c|c|c|c|c|c|c|}
\hline Catalyst & $\begin{array}{l}\text { Number } \\
\text { of uses }\end{array}$ & $\begin{array}{l}\text { Amount } \\
\text { of } \\
\text { catalyst } \\
\text { (mmol } \\
\text { Mn) }\end{array}$ & $\begin{array}{l}\text { Amount } \\
\text { of alkene } \\
(\mathrm{mmol})\end{array}$ & Time (h) & $\begin{array}{l}\text { Yield of } \\
\text { epoxide } \\
(\%)^{b}\end{array}$ & $\operatorname{Ee}(\%)^{c}$ \\
\hline 2 & $1 \mathrm{st}$ & 0.010 & 0.20 & $7.5^{d}$ & 100 & $\geq 94$ \\
\hline 1 & $1 \mathrm{st}$ & 0.010 & 0.20 & $6.5^{d}$ & 100 & $\geq 94$ \\
\hline Polymer 12 & $1 \mathrm{st}$ & 0.018 & 0.18 & 24 & 37 & ca. 94 \\
\hline , & $2 n d$ & 0.017 & 0.17 & 24 & 30 & ca. 94 \\
\hline , & $3 \mathrm{rd}$ & 0.010 & 0.10 & 48 & 70 & ca. 94 \\
\hline , & 4th & 0.009 & 0.09 & 48 & 38 & ca. 93 \\
\hline , & 5 th & 0.006 & 0.06 & $48^{e}$ & $70^{e}$ & ca. $90^{f}$ \\
\hline 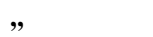 & 6 th & 0.005 & 0.05 & $48^{e}$ & $50^{e}$ & ca. $90^{f}$ \\
\hline
\end{tabular}

$a$ See note $\dagger .{ }^{b}$ The yield of epoxide was determined by gas chromatography (GC) using hexadecane as an internal standard. Estimated error limits $\pm 5 \%$. $c$ The enantiomeric excess was determined by the integration of peak areas in ${ }^{1} \mathrm{H}$ NMR spectra using the chiral shift reagent $\mathrm{Eu}(\mathrm{hfc})_{3}$ and the absolute configuration of the resultant epoxide, according to Katsuki, should be $1 S, 2 R .{ }^{9} d$ The total volume of solvent in these reactions was $2.5 \mathrm{ml}$. ${ }^{e}$ For these reactions the amount of solvent was reduced to $2 \mathrm{ml}$ (from $4 \mathrm{ml}$ ). ${ }^{f}$ The amount of product was so small that the ee values are less reliable.

polymer $\mathbf{1 2}$ after the full sequence of uses. It showed a slight increase in $\mathrm{Mn}$ content to $0.26 \mathrm{mmol} \mathrm{g}^{-1}$, consistent with anionexchange to a lighter anion such as chloride, but not with loss of complex from the polymer. However, there was also some evidence from its IR spectrum for some degradation of the polymer after six re-uses.

\section{Notes and references}

$\dagger \quad$ The following procedure for epoxidation of 1,2-dihydronaphthalene is general (Table 1 gives the actual scale used in each case). Polymer 12 was allowed to swell in $\mathrm{CH}_{2} \mathrm{Cl}_{2}(2 \mathrm{ml})$ for $1 \mathrm{~h}$. A solution containing 1,2-dihydronaphthalene (1 eq.), 4-PPNO (0.25 eq.) and hexadecane as internal standard in $\mathrm{CH}_{2} \mathrm{Cl}_{2}(2 \mathrm{ml})$ was added and the mixture was cooled to $0^{\circ} \mathrm{C}$. A solution of $\mathrm{NaOCl}$ in phosphate buffer $(0.588 \mathrm{M}, 5$ eq., $\mathrm{pH}=$ 11.4) was added and the mixture was stirred at $0{ }^{\circ} \mathrm{C}$. The progress of the reaction was monitored by GC. After the appropriate time the suspension was filtered off and washed with $\mathrm{CH}_{2} \mathrm{Cl}_{2}, \mathrm{H}_{2} \mathrm{O}$ and finally $\mathrm{MeOH}$. After being dried in a vacuum oven $\left(50{ }^{\circ} \mathrm{C} / 10 \mathrm{mmHg}\right.$ ) for $24 \mathrm{~h}$ the polymer was available for re-use.

The product was purified by column chromatography to give the epoxide as a cream coloured oil.

1 (a) E. M. Jacobsen, in: Catalytic Asymmetric Synthesis Ed. I. Oijima, VCH, New York, 1993, Chapter. 4.2, p 159; (b) E. N. Jacobsen and M. $\mathrm{H}$. Wu, in: Comprehensive Asymmetric Catalysis II, Eds. E. N. Jacobsen, A. Pfaltz and H. Yamamoto, Springer-Verlag, New York, 1999, Chapter 18.2, p. 649

2 (a) T. Katsuki, J. Mol. Catal. A: Chem., 1996, 113, 87; (b) T. Katsuki, Coord. Chem. Rev., 1995, 140, 189; (c) Y. N. Ito and T. Katsuki, Bull. Chem. Soc. Jpn., 1999, 72, 603; (d) T. Katsuki, in: Catalytic Asymmetric Synthesis, Ed. I. Oijima; VCH, New York, 2000, Chapter. 6.6B, p 287.

3 B. Pugin and H.-U. Blaser, in: Comprehensive Asymmetric Catalysis III Eds. E. N. Jacobsen, A. Pfaltz and H. Yamamoto, Springer-Verlag, New York, 1999, Chapter 38.1, p. 1367.

4 For reviews, see: (a) D. C. Sherrington, Catalysis Today, 2000, 57, 87; (b) B. Clapham, T. S. Reger and K. D. Janda, Tetrahedron, 2001, 57, 4637 (see Section 2.4).

5 J. Skarzewski, A. Gupta and A. Vogt, J. Mol. Catal. A: Chem., 1995, 103, 63.

6 H. Sasaki, R. Irie, T. Hamada, K. Suzuki and T. Katsuki, Tetrahedron, 1994, 50, 11827

7 J. Lopez, S. Liang and X. R. Bu, Tetrahedron Lett., 1998, 39, 4199.

8 J. M. Frechet and C. Schuerch, J. Am. Chem. Soc., 1971, 93, 492; X. Beebe, N. E. Schore and M. J. Kurth, J. Org. Chem., 1995, 60, 4196; T. M. Fyles and C. C. Leznoff, Can. J. Chem., 1978, 56, 1031.

9 T. Kuroki, T. Hamada and T. Katsuki, Chem. Lett., 1995, 339. 